\title{
ПОЛУЧЕНИЕ ГАПЛОИДНЫХ РАСТЕНИЙ Rubus arcticus L. МЕТОДОМ КУЛЬТУРЫ МИКРОСПОР in vitro
}

\author{
Д.Н. ЗОНТИКОВ ${ }^{1}$, С.А. ЗОНТИКОВА ${ }^{1}$, К.В. МАЛАХОВА ${ }^{1}$, Э.В. МАРАМОХИН ${ }^{1}$, \\ А.В. ПОЛЯКОВ 2 , Р.В. СЕРГЕЕВ 3
}

Княженика арктическая (Rubus arcticus L.) - ценная ягодная культура, которая используется в качестве плантационной культуры относительно короткое время. Княженика арктическая служит донором ремонтантности при межвидовой гибридизации с Rubus idaeus L., однако передает потомству низкую урожайность. Основное направление селекции $R$. arcticus - повышение урожайности растений, в связи с чем особое значение имеет ускорение селекционного процесса. Добиться этого можно, используя растения с удвоенным гаплоидным набором хромосом. В настоящей работе нами впервые были получены гаплоидные растения-регенеранты $\boldsymbol{R}$. $\operatorname{arcticus}$ в культуре микроспор, подобрана концентрация 6-бензиламинопурина и источник углеводного питания для индукции эмбриоидогенеза. Цель нашего исследования состояла в разработке методики получения гаплоидных растений Rubus arcticus в культуре микроспор. В опытах использовали сорта княженики арктической, выведенные селекционерами в Финляндии (Pima, Mespi) и Швеции (Astra). Для получения донорных эксплантов в течение всего года применяли метод выгонки генеративных побегов. Микроспоры из пыльников выделяли при помощи ручного гомогенизатора в микропробирки типа Эппендорф (1,5 мл), добавляли 0,5 мл стерильной воды с глюкозой в концентрации 30 г/л, центрифугировали при скорости 4500 об/мин и микродозатором переносили на питательные среды для активации морфогенеза. Для изоляции пыльников с последующим выделением микроспор использовали бутоны длиной от 90 до 120 мм за 4-5 сут до начала распускания цветка. Плотность микроспор в суспензии составляла около 40000 шт. в 0,5 мл стерильного водного раствора с глюкозой. Для получения такой плотности измельчали 60 пыльников. Для индукции эмбриоидогенеза микроспоры культивировали на среде Мурасиге-Скуга (МС), обогащенной 6-бензиламинопурином (6-БАП) в концентрациях от 0,50 до 2,00 мг/л. После появления эмбриоидов использовали среду МС с содержанием макро- и микроэлементов в полной концентрации и уменьшенной до 75 и 50 \% по прописи. Также исследовали влияние на рост и развитие эмбриоидов источника углеводного питания. Для этого использовали глюкозу, сахарозу и мальтозу в концентрациях 20, 30 и 40 г/л. В начале эксперимента подсчитывали число микроспор в пыльниках и определяли соотношение стадий развития микроспоры с длиной бутонов. При числе пыльников у R. arcticus от 70 до 86 и длине бутона от 1,0 до 1,4 мм, число зрелых пыльцевых зерен составляло от 590 до 710 шт. в одном пыльнике. Мы выделили четыре основные стадии развития микроспоры: тетрада; невакуолизированная микроспора с центральным локализованным расположения ядра; сильно вакуолизированная микроспора с утолщенной стенкой, крупной вакуолью и небольшим ядром, расположенным латерально; трехклеточная пыльца. На среде, содержащей 6-БАП в конщентрации 1,5 мг/л, эмбриоиды визуализировались на $51 \pm 2$-е сут культивирования, а их число достигало $23 \pm 3$ шт. Установлено влияние концентрации маточного раствора питательной среды и источника углеводного питания на рост эмбриоидов. Лучшие морфометрические показатели эмбриоидов получили в варианте с концентрацией макроэлементов по прописи МС 0,75 и глюкозой в концентрации 30 г/л. В этом варианте рост эмбриоидов отмечали на

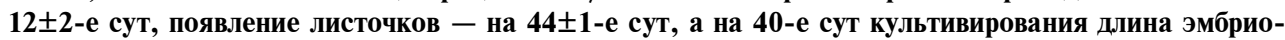
идов достигала $5 \pm 0,2$ мм. Для контроля плоидности полученных растений-регенерантов использовали прямой метод подсчета хромосом и косвенный - подсчет хлоропластов в замыкающих клетках устьиц. В результате подсчета был подтвержден гаплоидный набор хромосом полученных растений-регенерантов $(n=7)$. Результаты исследования позволяют использовать предложенный метод при получении гаплоидных растений $R$. arcticus, которые после удвоения хромосомного набора могут быть включены в селекционный процесс.

Ключевые слова: Rubus arcticus, гаплоид, диплоид, культура микроспор, эмбриоид, морфогенез, растение-регенерант.

Княженика арктическая (Rubus arcticus L.) относится к ценным ягодным растениям. Несмотря на относительно небольшой срок ее ис-

* Работа выполнялась при поддержке РФФИ (проект № 18-416-440002 р_а). 
пользования в качестве плантационной культуры, получено несколько высокопродуктивных сортов. Княженика арктическая служит донором ремонтантности и отличных вкусовых качеств при межвидовой гибридизации с Rubus idaeus L., однако передает потомству низкую урожайность. Основное направление селекции $R$. arcticus - повышение урожайности растений, в связи с чем ускорение селекционного процесса и использование гаплоидов для селекции перекрестноопыляемых растений имеет особое значение (1-3). Применение технологии удвоенных гаплоидов позволяет преодолеть ряд селекционных трудностей. Гомозиготные линии на основе гаплоидов могут быть получены за 2-3 года (4). При этом, по мнению ряда исследователей, использование андроклинных регенерантов - единственный способ сохранить гетерозисный эффект ценной гибридной линии (5).

Работы, посвященные проблеме получения гаплоидных растений, объединяет общий план построения опытов: воздействие повышенными и/или пониженными температурами, химическая обработка донорных растений, изменение состава питательной среды (регуляторов роста, углеводных составляющих), подбор возрастной стадии развития пыльника и микроспоры. К настоящему времени опубликованы методики получения гаплоидных растений пшеницы $(5,6)$, капусты (7-9), рапса (10), риса (11), моркови (12-14). Работы, посвященные получению гаплоидных растений $R$. arcticus L. в культуре микроспор, отсутствуют.

Факторов, влияющих на активизацию процессов переключения микроспор с гаметофитного пути развития на спорофитный, очень много, например, влияние видов и концентраций регуляторов роста (15-17), источников углеводного питания (18-20).

Ранее нами были предложены методические подходы для клонального микроразмножения $R$. arcticus (21). В развитие этих исследований в настоящей работе мы впервые получили гаплоидные растения-регенеранты $R$. arcticus в культуре микроспор, оптимизировав концентрацию 6бензиламинопурина и источник углеводного питания для индукции эмбриоидогенеза.

Нашей целью была разработке методики получения гаплоидных растений Rubus arcticus L. в культуре микроспор.

Методика. Исследования проводили в 2018 году. Использовали сорта княженики арктической Пима (Рima), Меспи (Mespi), выведенные в Финляндии, и Астра (Astra) из Швеции. Микроспоры выделяли из пыльников, которые отбирали из бутонов разного возраста и размера.

Для снижения контаминации при введении в культуру in vitro и возможности круглогодичного получения бутонов использовали метод выгонки (22), при котором растения, высаженные в горшки, после завершения цветения инкубировали в течение 30 сут при температуре $4{ }^{\circ} \mathrm{C}$. После холодовой обработки такие растения снова образовывали генеративные побеги.

Стерилизацию бутонов проводили по схеме: 1 мин в $70 \%$ водном растворе этанола, 15 мин в $5 \%$ водном растворе гипохлорита натрия или калия, затем их промывали в стерильной дистиллированной воде не менее трех раз. Выделенные пыльники собирали в микропробирки типа Эппендорф объемом 1,5 мл по 60 шт. и измельчали с помощью ручного гомогенизатора, одноканальным микродозатором Proline 20-200 («Sartorius Proline», Финляндия) добавляли 0,5 мл стерильной воды с глюкозой в концентрации 30 г/л. После этого пробирки центрифугировали (мини- 
центрифуга-вортекс Microspin FV-2400, SIA «BioSan», Латвия) 15 с при 4500 об/мин. Из каждой пробирки микродозатором переносили суспензию с микроспорами в культуральный сосуд объемом 10 мл (суспензию из одной пробирки помещали в один культуральный сосуд). Плотность суспензии составляла примерно 80000 микроспор/мл. Для изоляции пыльников с последующим выделением микроспор использовали бутоны длиной от 9 до 12 мм за 4-5 сут до начала распускания.

На каждом этапе in vitro культивирования микроспор менялся состав питательной среды и используемых регуляторов роста. При введении в культуру in vitro для активации морфогенеза использовали питательную среду Мурасиге-Скуга (МС) (23), дополненную 100 мг/л мезоинозита, 2 мг/л глицина, 0,5 мг/л тиамина, 0,5 мг/л пиридоксина, 30 г/л глюкозы и 5,0 г/л агара, $\mathrm{pH}$ от 5,8. В качестве регулятора роста использовали 6-бензиламинопурин (6-БАП) в концентрации от 0,50 до 2,00 мг/л («AppliChem $\mathrm{GmbH»,} \mathrm{Германия).} \mathrm{После} \mathrm{появления} \mathrm{эмбриоидов} \mathrm{использовали} \mathrm{среду} \mathrm{МС}$ («AppliChem GmbH», Германия) с содержанием макро- и микроэлементов в полной концентрации и в уменьшенной до 75 и $50 \%$ по прописи (23). При исследовании влияние источника углеводного питания на рост и развитие эмбриоидов использовали глюкозу, сахарозу и мальтозу в концентрациях 20, 30 и 40 г/л.

Микроспоры, эмбриоиды и растения-регенеранты выращивали при освещенности 1500 лк, фотопериоде 16 ч (день)/8 ч (ночь) и температуре около $25^{\circ} \mathrm{C}$. На этапе введения в культуру in vitro, роста и развития эмбриоидов использовали стеклянные культуральные сосуды объемом 10 мл, на этапе роста растений-регенерантов - культуральные сосуды объемом 100 мл.

Хромосомы подсчитывали в меристемной зоне корня растенийрегенерантов. Корни помещали в фиксатор Карнуа (24) и выдерживали в течение 24 ч. Затем промывали в течение 20 мин под проточной водой, помещали в смесь ферментов (0,3 \% пектиназы, 0,3 \% мацеразы, 0,3\% целюлазы + цитратный буфер) и инкубировали в течение 2 ч при температуре $37{ }^{\circ} \mathrm{C}$. После этого корни на 3 мин помещали в $60 \%$ уксусную кислоту, где материал измельчали препаровальной иглой, обводили фиксатором 3:1, встряхивали, промывали в абсолютном спирте, подсушивали, окрашивали метиленовым синим, промывали в дистиллированной воде и подсчитывали число хромосом (24) (световой микроскоп Биомед-3, «Биомед», Россия). Для подсчета числа хлоропластов использовали высечки из листьев диаметром 5 мм, с каждого растения делали по 5 высечек. Высечки окрашивали йодным красителем. Растущие в культуре in vitro растения-регенеранты фотографировали цифровой камерой Samsung NX-10 («Samsung», Южная Корея).

Экспериментальные данные представлены в виде средних арифметических значений $(M)$ с указанием ошибки среднего ( $\pm \mathrm{SEM})$ и коэффициента вариации $(C v)$. Расчет доверительного интервала на основании $t$ распределения Стьюдента при уровне значимости $\mathrm{p} \leq 0,05$ проводили с использованием статистического пакета программы Microsoft Excel 2010.

Результаты. В начале эксперимента подсчитывали число микроспор в пыльниках и сопоставляли стадии развития микроспоры с длиной бутонов. При числе пыльников у $R$. arcticus от 70 до 86 шт. и длине бутона от 1,0 до 1,4 мм количество зрелой пыльцы в одном пыльнике составляло от 590 до 710 шт. Мы выделили четыре основных стадии развития 
микроспоры (рис. 1): 1-я стадия - тетрада (в бутонах длиной от 4 до 5 мм); 2-я стадия - невакуолизированная микроспора с центральным локализованным расположения ядра (в бутонах от 5 до 7 мм); 3-я стадия сильно вакуолизированная микроспора с утолщенной стенкой, крупной вакуолью и небольшим ядром, расположенным латерально (в бутонах от 7 до 8 мм); 4-я стадия - трехклеточная пыльца (в бутонах длиной более 8 мМ) (рис. 1).

A

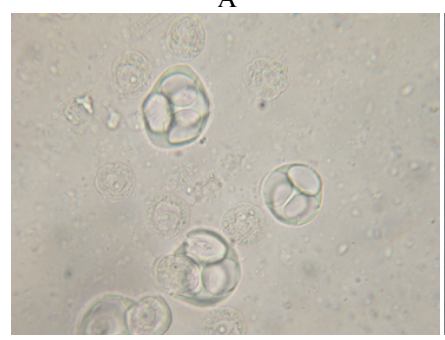

Б

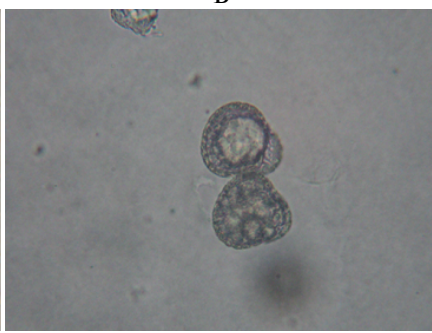

B

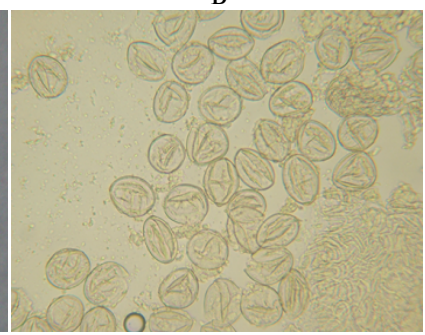

Рис. 1. Микроспоры княженики арктической (Rubus arcticus L.) сорта Astra на питательной среде Мурасиге-Скуга (сахароза - 30 г/л, 6-бензиламинопурин - 1,5 мг/л, рН 5,8): А - стадия тетрады, Б - сильно вакуолизированная микроспора, В - зрелая пыльца (увеличение $\times 600$, световой микроскоп Биомед-3, «Биомед», Россия).

1. Морфогенез микроспор княженики арктической (Rubus arcticus L.) разных сортов на питательной среде Мурасиге-Скуга в зависимости от конщентрации 6-бензиламинопурина (6-БАП)

\begin{tabular}{|c|c|c|c|c|c|}
\hline \multirow[t]{2}{*}{ Сорт } & \multirow{2}{*}{$\begin{array}{l}\text { Концентрация } \\
\text { 6-БАП, мг/л }\end{array}$} & \multicolumn{2}{|c|}{ Появление эмбриоидов, сут } & \multicolumn{2}{|c|}{$\begin{array}{l}\text { Число эмбриоидов, образовавшихся } \\
\text { на } 60 \text {-е сут, шт. }\end{array}$} \\
\hline & & $M \pm \mathrm{SEM}^{1,2}$ & $C v, \%$ & $M \pm \mathrm{SEM}^{1,2}$ & $C v, \%$ \\
\hline \multirow[t]{7}{*}{ Astra } & 0,50 & $63 \pm 2^{\mathrm{a}}$ & 7,8 & $5 \pm 1^{\mathrm{c}}$ & 11,2 \\
\hline & 0,75 & $58 \pm 1^{\mathrm{ab}}$ & 4,5 & $12 \pm 2^{\mathrm{ac}}$ & 4,5 \\
\hline & 1,00 & $55 \pm 1^{b c}$ & 10,0 & $14 \pm 2^{\mathrm{ac}}$ & 6,3 \\
\hline & 1,25 & $51 \pm 2^{c}$ & 9,2 & $23 \pm 3^{b}$ & 5,6 \\
\hline & 1,50 & $51 \pm 3^{\mathrm{bc}}$ & 7,8 & $20 \pm 1^{b}$ & 7,2 \\
\hline & 1,75 & $51 \pm 3^{\mathrm{bc}}$ & 8,2 & $9 \pm 2^{c}$ & 8,7 \\
\hline & 2,00 & 0 & 0 & 0 & 0 \\
\hline \multirow[t]{7}{*}{ Pima } & 0,50 & $65 \pm 3$ & 2,6 & $4 \pm 1^{\mathrm{a}}$ & 9,1 \\
\hline & 0,75 & $54 \pm 2^{\mathrm{a}}$ & 4,6 & $7 \pm 2^{\mathrm{ab}}$ & 12,4 \\
\hline & 1,00 & $53 \pm 2^{\mathrm{a}}$ & 7,1 & $8 \pm 2^{\mathrm{ab}}$ & 9,3 \\
\hline & 1,25 & $53 \pm 1^{\mathrm{a}}$ & 8,6 & $18 \pm 1$ & 9,7 \\
\hline & 1,50 & $54 \pm 2^{\mathrm{a}}$ & 5,8 & $9 \pm 1^{b}$ & 6,5 \\
\hline & 1,75 & $54 \pm 2^{\mathrm{a}}$ & 4,3 & $8 \pm 2^{\mathrm{ab}}$ & 7,7 \\
\hline & 2,00 & - & - & - & - \\
\hline \multirow[t]{7}{*}{ Mespi } & 0,50 & $63 \pm 2^{\mathrm{a}}$ & 12,2 & $10 \pm 2^{\mathrm{a}}$ & 5,4 \\
\hline & 0,75 & $60 \pm 1^{\mathrm{a}}$ & 12,1 & $13 \pm 2^{\mathrm{ab}}$ & 6,5 \\
\hline & 1,00 & $57 \pm 2^{\mathrm{ab}}$ & 10,1 & $15 \pm 2^{\mathrm{ab}}$ & 6,4 \\
\hline & 1,25 & $53 \pm 2^{b}$ & 9,3 & $20 \pm 1$ & 7,6 \\
\hline & 1,50 & $52 \pm 1^{b}$ & 6,5 & $14 \pm 1^{b}$ & 3,8 \\
\hline & 1,75 & $53 \pm 2^{b}$ & 3,4 & $14 \pm 2^{b}$ & 5,1 \\
\hline & 2,00 & $63 \pm 2^{\mathrm{a}}$ & 7,8 & $5 \pm 1^{\mathrm{c}}$ & 11,2 \\
\hline \multicolumn{6}{|c|}{$\begin{array}{l}\text { П р и м е ч а н и е. Концентрация сахарозы }-30 \text { г/л, рН 5,8. Каждый вариант опыта выполнен в } 3 \text {-крат- } \\
\text { ной повторности, плотность микроспор } 40000 \text { в } 0,5 \text { мл. Прочерки означают гибель эксплантов. } 1-\text { дове- } \\
\text { рительный интервал на основе } t \text {-распределения Стьюдента при р } \leq 0,05 ; 2-\text { показатели в столбце, отме- } \\
\text { ченные одинаковыми буквами }(\mathrm{a}, \mathrm{b}, \mathrm{c}) \text {, не имеют статистически значимых различий при } \mathrm{p} \leq 0,05 \text { согласно } \\
t \text {-критерию Стьюдента. }\end{array}$} \\
\hline
\end{tabular}

Наибольшее число образовавшихся эмбриоидов на 50-53 сут культивирования было достоверно больше во всех сортах на среде, содержащей 6-БАП в концентрации 1,5 мг/л (табл. 1). Визуально эмбриоиды обнаруживали, начиная со стадии «сердечко», когда их размер достигал 0,5 мм. Достоверного влияния генотипа на морфогенез микроспор в культуре in vitro мы не выявили. Специального изучения влияния стадии развития 
микроспоры на морфогенетическую активность мы не проводили. Необходимо отметить только то, что микроспоры, которые помещали на питательную среду, в подавляющем большинстве находились на стадии вакуолизации.

В исследованиях для индукции эмбриогенеза и получения вторичных эмбриоидов активно используются разные концентрации 6-БАП в качестве регулятора роста (25). В нашей работе 6-БАП индуцировал прямой эмбриоидогенез.
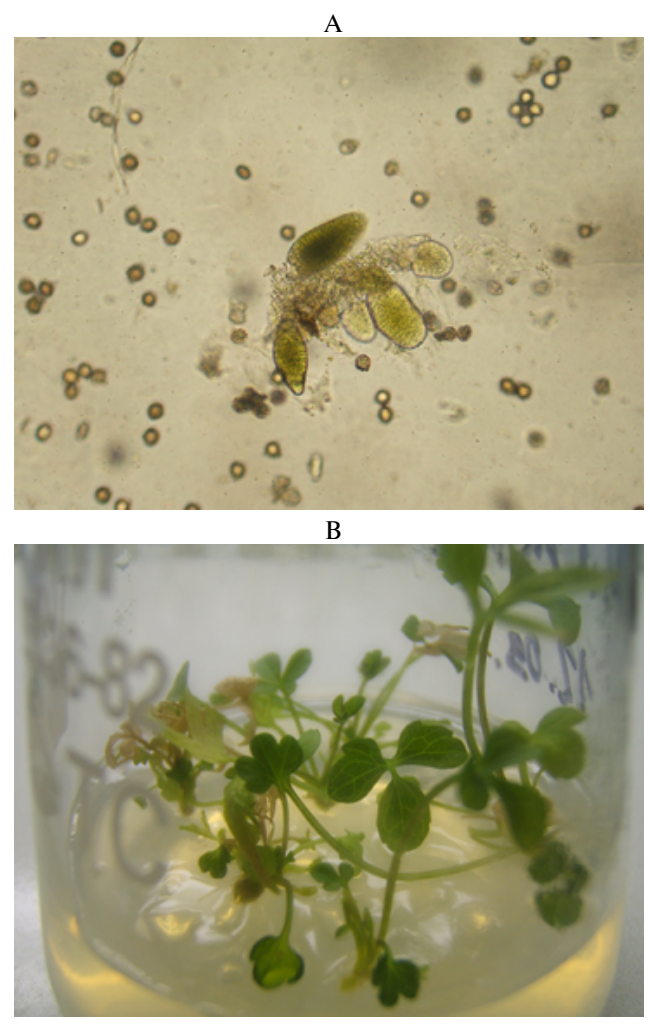

Б

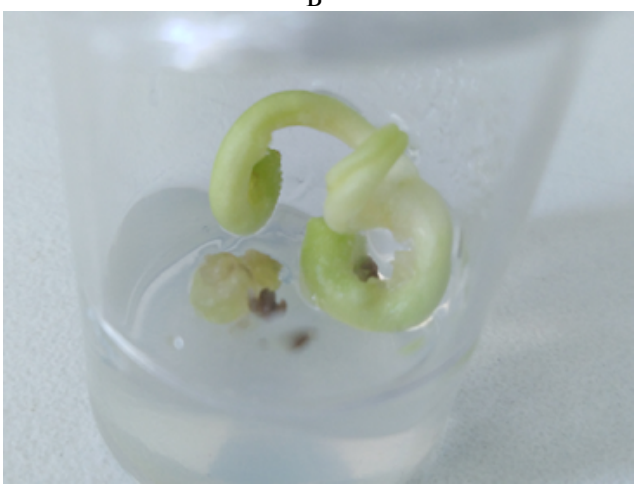

Рис. 2. Этапы развития гаплоидов княженики арктической (Rubus arcticus L.) сорта Astra в культуре in vitro на питательной среде Мурасиге-Скуга: А - эмбриоиды на стадии сердечко и торпедо (6-бензиламинопурин 1,5 мг/л, рН 5,8; увеличение $\times 100$, световой микроскоп Биомед-3, «Биомед», Россия), Б эмбриоид, длина 5 мм (6-бензиламинопурин - 1,5 мг/л, pН 5,8, глюкоза - 30 г/л); В растение-регенерант (6-бензиламинопурин 1,5 мг/л, рН 5,8, глюкоза - 30 г/л).

Нами также установлено, что более интенсивные ростовые процессы происходили на питательной среде с содержанием макро- и мик-

роэлементов, уменышенным до 75 \%, при концентрации глюкозы 30 г/л. В этом варианте рост эмбриоидов отмечали на 12-е сут культивирования, что достоверно отличалось от других вариантов. На 40-е сут их размер достигал 5 мм (рис. 2). Однако наименьшая гибель эмбриоидов наблюдалась на среде с полным составом макро- и микроэлементов (табл. 2).

2. Рост эмбриоидов княженики арктической (Rubus arcticus L.) сорта Astra в культуре in vitro на питательной среде Мурасиге-Скуга в зависимости от концентрации макро- и микроэлементов и источника углеводного питания

\begin{tabular}{|c|c|c|c|c|c|c|c|}
\hline \multirow{2}{*}{$\begin{array}{l}\text { Концентрация } \\
\text { макро- и мик- } \\
\text { роэлементов, \% }\end{array}$} & \multirow{2}{*}{$\begin{array}{l}\text { Вид и кон- } \\
\text { центрация } \\
\text { углеводов, г/л }\end{array}$} & \multicolumn{2}{|c|}{$\begin{array}{l}\text { Начало роста } \\
\text { эмбриоидоидов, сут }\end{array}$} & \multicolumn{2}{|c|}{$\begin{array}{l}\text { Появление } \\
\text { листочков, сут }\end{array}$} & \multicolumn{2}{|c|}{$\begin{array}{l}\text { Общая длина через } 40 \text { сут } \\
\text { культивирования, мм }\end{array}$} \\
\hline & & $M \pm \mathrm{SEM}^{1,2}$ & $C v, \%$ & $M \pm \mathrm{SEM}^{1,2}$ & $C v, \%$ & $M \pm$ SEM $^{1,2}$ & $C v, \%$ \\
\hline \multirow[t]{9}{*}{100} & Сахароза, 20 & $55 \pm 3$ & 13,2 & - & - & $1,0 \pm 0,5^{\mathrm{a}}$ & 29,1 \\
\hline & Сахароза, 30 & $41 \pm 2^{a}$ & 10,3 & - & - & $1,0 \pm 0,5^{\mathrm{a}}$ & 11,3 \\
\hline & Сахароза, 40 & $40 \pm 1^{\mathrm{a}}$ & 5,4 & $63 \pm 3^{a}$ & 3,4 & $2,0 \pm 0,6^{\mathrm{ab}}$ & 7,1 \\
\hline & Мальтоза, 20 & $37 \pm 2^{a}$ & 12,3 & $60 \pm 3^{a}$ & 7,6 & $3,0 \pm 0,3^{\mathrm{b}}$ & 5,3 \\
\hline & Мальтоза, 30 & $19 \pm 1^{b}$ & 5,4 & $49 \pm 2^{b}$ & 2,1 & $3.0 \pm 0,5^{b}$ & 5,6 \\
\hline & Мальтоза, 40 & $20 \pm 1^{\mathrm{b}}$ & 4,2 & $49 \pm 3^{b}$ & 6,4 & $4.0 \pm 0,5^{b}$ & 8,0 \\
\hline & Глюкоза, 20 & $25 \pm 3^{b}$ & 14,1 & $49 \pm 4^{\mathrm{ab}}$ & 11,9 & $2,0 \pm 1,0^{\mathrm{ab}}$ & 14,6 \\
\hline & Глюкоза, 30 & $17 \pm 2^{\mathrm{b}}$ & 10,2 & $47 \pm 4^{\mathrm{ab}}$ & 9,5 & $3,0 \pm 0,3^{\mathrm{b}}$ & 7,5 \\
\hline & Глюкоза, 40 & $20 \pm 2^{b}$ & 9,8 & $48 \pm 4^{b}$ & 8,7 & $4,0 \pm 0,4^{\mathrm{b}}$ & 5,9 \\
\hline
\end{tabular}


Глюкоза, 20

Глюкоза, 30

Глюкоза, 40

Глюкоза, 30

Глюкоза, 40

$\begin{array}{cccc}- & - & - & - \\ 43 \pm 3^{\mathrm{a}} & 6,8 & 60 \pm 3^{\mathrm{a}} & 13,2 \\ 40 \pm 2^{\mathrm{a}} & 8,2 & 60 \pm 4^{\mathrm{a}} & 12,5 \\ - & - & - & - \\ 21 \pm 2^{\mathrm{b}} & 5,5 & 46 \pm 2^{\mathrm{b}} & 5,6 \\ 20 \pm 2^{\mathrm{b}} & 4,3 & 46 \pm 2^{\mathrm{b}} & 8,1 \\ 25 \pm 3^{\mathrm{b}} & 11,2 & 46 \pm 3^{\mathrm{b}} & 10,3 \\ 12 \pm 2^{\mathrm{c}} & 5,2 & 44 \pm 1^{\mathrm{b}} & 7,0 \\ 15 \pm 2^{\mathrm{c}} & 8,7 & 45 \pm 2^{\mathrm{b}} & 6,2 \\ - & - & - & - \\ - & - & - & - \\ 52 \pm 2^{\mathrm{a}} & 10,3 & 80 \pm 5^{\mathrm{a}} & 12,5 \\ - & - & - & - \\ 58 \pm 1 & 5,4 & 73 \pm 2^{\mathrm{a}} & 6,7 \\ 50 \pm 2^{\mathrm{a}} & 7,9 & 70 \pm 1^{\mathrm{a}} & 8,3 \\ 41 \pm 2^{\mathrm{b}} & 6,3 & - & - \\ 39 \pm 2^{\mathrm{b}} & 7,5 & - & - \\ 35 \pm 3^{\mathrm{b}} & 4,3 & 62 \pm 2 & 5,9\end{array}$

Продолжение таблицы 2 П р и м е ч а н и е. Концентрация 6-бензиламинопурина - 1,5 мг/л, pH 5,8. Каждый вариант опыта выоснове $t$-распределения Стьюдента при $\mathrm{p} \leq 0,05 ; 2$ - показатели в столбце, отмеченные одинаковыми буквами $(\mathrm{a}, \mathrm{b}, \mathrm{c})$, не имеют статистически значимых различий при $\mathrm{p} \leq 0,05$ согласно $t$-критерию Стьюдента.

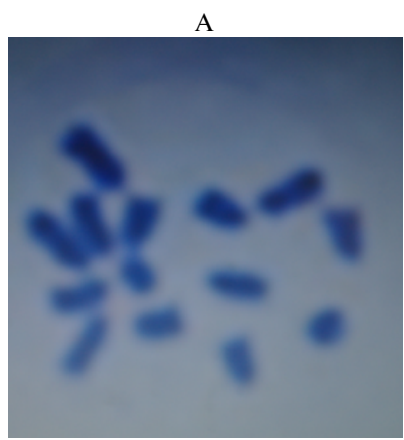

B
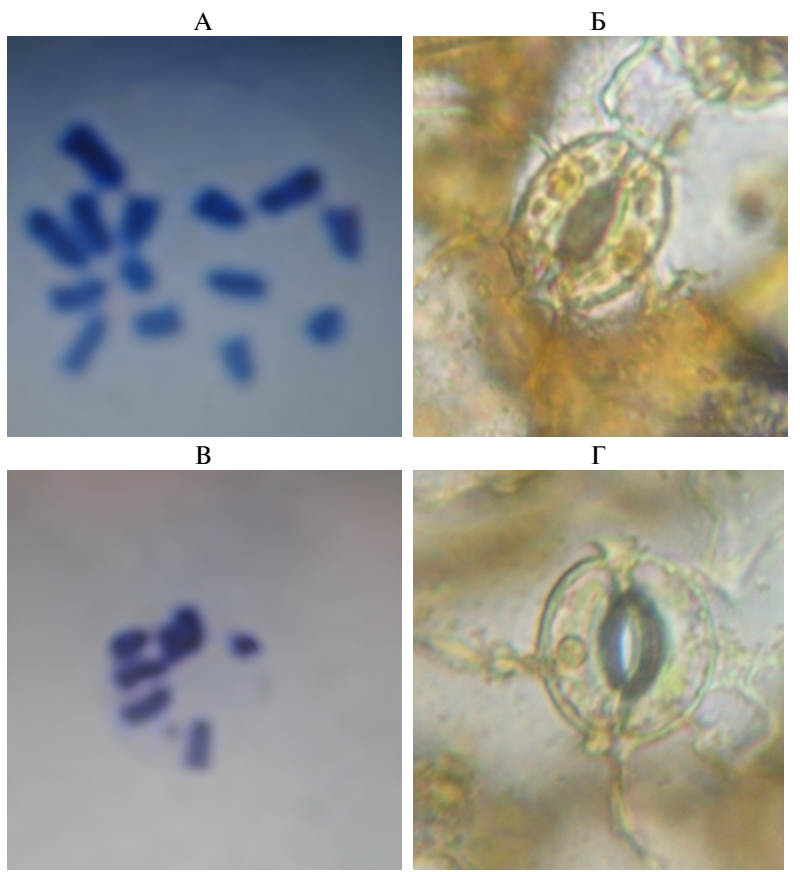

Рис. 3. Хромосомы делящихся клеток меристематической зоны корня на стадии метафазы (А, В, увеличение $\times 1000)$ и замыкающие клетки устьиц с хлоропластами (Б, Г, увеличение $\times 630)$ у полученных растений-регенерантов княженики арктической (Rubus arcticus L.) сорта Astra: A, Б диплоид $(2 n=14$, число хлоропластов в замыкающих клетках -10$)$, В, Г - гаплоид $(n=7$, число хлоропластов в замыкающих клетках - 4). Световой микроскоп Биомед-3 («Биомед», Россия). устьиц у диплоидных растений составляло от 8 до 12 шт., у гаплоидных от 2 до 6 шт. Возможность использования косвенного метода для подтверждения плоидности доказана в ряде работ (29-31).

Проведенные исследования не позволяют идентифицировать, на какой именно стадии развития микроспоры лучше получать гаплоидные
Многие авторы отмечают положительное влияние повышенного осмотического давления, которое создается при концентрациях сахарозы от 10 до $17 \%$, на появление эмбриоидов (26-28), однако в наших опытах эмбриоидогенез у $R$. arcticus активно происходил при концентрации $3 \%$, а уже при $4 \%$ скорость развития уменьшалась. Такое расхождение в результатах может объясняется тем, что мы изучали этап перехода от стадии эмбриоида к растению-регенеранту, а не этап образования эмбриоида из микроспоры.

Плоидность растений-регенерантов определяли подсчетом числа хромосом и числа хлоропластов в замыкающих клетках устьиц (рис. 3). Варьирование по числу хлоропластов в замыкающих клетках 
растения княженики, однако это имеет важное значение для определения факторов, влияющих на переключение программы развития микроспоры с гаметофитной на спорофитную $(17,19,28,32)$. Можно только отметить, что большая часть микроспор находилась на стадии вакуолизации. Одним из основных факторов переключения на спорофитный путь развития у микроспор княженики было использование регулятора роста 6-бензиламинопурина и глюкозы в качестве источника углеводного питания. Критически важным моментом при получении гаплоидных растений становится не только получение эмбриоидов, но и сохранение их жизнеспособности и морфогенетической активности при переносе на свежую питательную среду (33). Согласно нашим результатам, для его успешного прохождения необходимо снижение концентрации макро- и микроэлементов в питательной среде до $75 \%$, тогда как уменьшение до $50 \%$ приводит к снижению жизнеспособности.

Таким образом, для получения гаплоидных растений-регенерантов Rubus arcticus L. сортов Pims, Mespi и Astra целесообразно использовать питательную среду Мурасиге-Скуга, обогащенную 6-бензиламинопурином в концентрации 1,5 мг/л, что дает выход от $18 \pm 1$ до $23 \pm 3$ эмбриоидов на 40000 микроспор. Для получения растений-регенерантов из эмбриоидов необходимо использовать среду Мурасиге-Скуга с уменышенным до $75 \%$ содержанием макро- и микроэлементов, глюкозу в концентрации 3040 г/л, 6-бензиламинопурин - 1,5 мг/л, что позволяет индуцировать рост эмбриоидов за самое короткое время культивирования, а к 40-м сут полу-

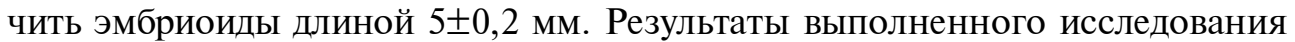
и предложенная нами методика могут использоваться при создании удвоенных гаплоидов других сортов $R$. arcticus для включении в селекционногенетические программы.

\footnotetext{
1ФГБОУ ВО Костромской государственный университет, 156005 Россия, г. Кострома, ул. Дзержинского, 17, e-mail: info@kstu.edu.ru, zontikovdn@mail.ru $\bowtie$, antennaria@mail.ru, maramokhin91@mail.ru, malakhova.kv1@gmail.com;

${ }^{2}$ Всероссийский НИИ овощеводства -

филиал ФГБНУ Федеральный научный центр овощеводства,

140153 Россия, Московская обл., Раменский р-н, д. Верея, стр. 500,

e-mail: vita100plus@yandex.ru;

ЗФГБОУ ВО Поволжсский государственный

технологический университет,

424000 Россия, Республика Марий Эл, г. Йошкар-Ола, пл. Ленина, 3,

e-mail: info@volgatech.net, rsergeyev@yahoo.com
}

Поступила в редакцию 25 марта 2019 года

Sel'skokhozyaistvennaya biologiya [Agricultural Biology], 2020, V. 55, № 1, pp. 128-136

\title{
GENERATION OF Rubus arcticus L. HAPLOIDS THROUGH in vitro MICROSPORE CULTURE TECHNIQUE
}

\author{
D.N. Zontikov' ${ }^{1}$, S.A. Zontikova ${ }^{1}$, K.V. Malahova ${ }^{1}$, E.V. Maramohin ${ }^{1}$, A.V. Poliykov², \\ R.V. Sergeev ${ }^{3}$
}

${ }^{1}$ Kostroma State University, 17, ul. Dzerzhinskogo, Kostroma, 156005 Russia, e-mail info@kstu.edu.ru, zontikovdn@mail.ru (corresponding author $₫$ ), antennaria@mail.ru, maramokhin91@mail.ru, malakhova.kv1@gmail.com;

${ }^{2}$ All-Russian Research Institute of Vegetable Growing - Branch of the Federal Scientific Vegetable Center, str. 500, Vereya, Ramenskii District, Moscow Province, 140153 Russia, e-mail vita100plus@yandex.ru;

${ }^{3}$ Volga State University of Technology, 3, pl. Lenina, Yoshkar-Ola, Republic of Mari El, 424000 Russia, e-mail info@volgatech.net, rsergeyev@yahoo.com

ORCID:

Zontikov D.N. orcid.org/0000-0002-6668-4877

Zontikova S.A. orcid.org/0000-0001-6566-4498

Malahova K.V. orcid.org/0000-0002-7762-8811

Maramohin E.V. orcid.org/0000-0002-1963-5845

The authors declare no conflict of interests 


\section{Abstract}

Arctic raspberry (Rubus arcticus L.) is a valuable small-fruit crop used as a plantation crop for a relatively short time. $R$. arcticus is a remontant donor in interspecific hybridization with Rubus idaeus L., though conditioning low yields to hybrids. So $R$. arcticus is primarily bred for yield enhancement; therefor, the acceleration of the breeding process is of great importance. This can be achieved using plants with a doubled haploid set of chromosomes. This paper is the first to describe the technique of production haploid plants of $R$. arcticus via in vitro microspore culture. In the experiments we used Finnish cultivars Pima and Mespi and Swedish cultivar Astra. To obtain donor explants, the method of forcing generative shoots was used throughout the year. Microspores were isolated from anthers with the use of manual homogenizer into a $1.5 \mathrm{ml}$ micro test Eppendorf tube. The homogenate was added with $0.5 \mathrm{ml}$ sterile water containing $30 \mathrm{~g} / 1$ glucose, centrifuged at $4500 \mathrm{rpm}$, and the microspores were transferred with a microdoser to nutrient medium for morphogenesis initiation. To obtain microspores, the anthers were isolated from buds of 90 to $120 \mathrm{~mm}$ long 4-5 days before the flower bloomed. The concentration of the microspores in the suspension was about 40,000 per $0.5 \mathrm{ml}$ sterile aqueous solution with glucose; for this, 60 anthers were crushed. To induce embryoidogenesis, we used the Murashige and Skoog (MS) plant growth medium supplemented with 0.50 to $2.00 \mathrm{mg} / \mathrm{l}$ growth regulator 6-benzylaminopurine (6-BAP). After the appearance of embryoids, we used MS, $75 \% \mathrm{MS}$, or $50 \% \mathrm{MS}$ growth media, and also the effect of carbohydrate sources, i.e. glucose, sucrose and maltose at a 20,30 and $40 \mathrm{~g} / 1$ dosage, was investigated. We have identified the following microspore development stages: tetrads, non-vacuolated microspore, strongly vacuolated microspore, three-cell pollen. It was found that MS nutrient media containing $1.5 \mathrm{mg} / 16$-BAP provides for $23 \pm 3$ embryoids on day $51 \pm 2$ of culture. We have also found the effect of MS concentration and the source of carbohydrate nutrition on the growth of embryoids. The combination of $0.75 \mathrm{MS}$ and $30 \mathrm{~g} / 1$ glucose was the most effective leading to embryoid growth on day $12 \pm 2$ and the appearance of leaflets on day $44 \pm 1$. On day 40 of culture the embryoids reached $5 \pm 0.2 \mathrm{~mm}$ in length. The ploidy control of regenerant plants, by counting chromosomes and chloroplasts in the stomata guard cells, confirmed the haploid set of chromosomes $(n=7)$. These findings allow the use of the proposed technique to generate $R$. arcticus haploids which, after doubling the chromosome set, may be involved in breeding.

Keywords: Rubus arcticus, haploid, diploid, microspore culture, embryoid, morphogenesis, regenerant plant.

\section{R E F EREN C ES}

1. Tyak G.V. Primenenie mineral'nykh udobrenii v posadkakh knyazheniki na vyrabotannom torfyanike. Materialy Mezhdunarodnoi nauchno-prakticheskoi konferentsii «Teoreticheskie $i$ prikladnye aspekty ratsional'nogo ispol'zovaniya $i$ vosproizvodstva nedrevesnoi produktsii lesa» [Proc. Int. Conf. «Theoretical and applied aspects of rational use and reproduction of nontimber forest products»]. Gomel', 2008: 305-308 (in Russ.).

2. Karp K., Starast M. The Artic bramble (Rubus arcticus L.) cultivated in Estonia. Proc. Int. Conf. "Problems of rational utilization and reproduction of berry plants in boreal forests on the eve of the XXI century». Belarus, Gomel, 1997: 158-160.

3. Vool E., Noormets M., Karp K., Mand R., Starast M. Pollinators and their foraging behavior in arctic bramble (Rubus arcticus L.) plantations in Estonia. Proc. International Conference "Integrative approaches towards sustainability in the Baltic Sea Region». Latvia, 2003: 481-489.

4. Dvoryadkina A.G. Gaploidiya u kleshcheviny kak metod sozdaniya gomozigotnykh form $v$ tselyakh selektsii. Avtoreferat kandidatskoi dissertatsii [Castor bean haploidy as a method for creating homozygous forms for breeding purposes. PhD Thesis]. Krasnodar, 1972 (in Russ.).

5. Kruglova N.N. Embriologicheskie osnovy androklinii pshenitsy [Embryological basis of androkline wheat]. Moscow, 2005 (in Russ.).

6. Kim K.-M., Baenziger P. A simple wheat haploid and doubled haploid production system using anther culture. In Vitro Cellular \& Developmental Biology - Plant, 2005, 41(1): 22-27 (doi: 10.1079/IVP2004594).

7. Duijs J.G., Voorrips R.E. Highly regenerative cultivars in microspore culture in Brassica oleraseae L. var. Capitata. Euphytica, 1992, 60: 45-55.

8. Domblides E.A., Shmykova N.A. Sbornik nauchnykh trudov Vserossiiskogo NII selektsii i semenovodstva ovoshchnykh kul'tur. Moscow, 2002, vyp. 37: 82-92 (in Russ.).

9. Gu H., Zhao Z., Sheng X., Yu H., Wang J. Efficient doubled haploid production in microspore culture of loose-curd cauliflower (Brassica oleracea var. botrytis). Euphytica, 2014, 195(3): 467 475 (doi: 10.1007/s10681-013-1008-x).

10. Mandal A. Induction of androgenetic haploids in the breeding materials of winter rape (Brassica 
napus). Hereditas, 2008, 106(2): 189-193.

11. Ilyushko M.V., Skaptsov M.V., Romashova M.V. Nuclear DNA content in rice (Oryza sativa L.), regenerants derived from anther culture in vitro. Sel'skokhozyaistvennaya biologiya [Agricultural Biology], 2018, 53(3): 531-538 (doi: 10.15389/agrobiology.2018.3.531eng).

12. Kiszczak W., Kowalska U., Kapuścińska A., Burian M., Górecka K. Comparison of methods for obtaining doubled haploids of carrot. Acta Societatis Botanicorum Poloniae, 2017, 86(2): 3547 (doi: 10.5586/asbp.3547).

13. Shmykova N.A. Sel'skokhozyaistvennaya biologiya [Agricultural Biology], 2001, 5: 53-60 (in Russ.).

14. Tyukavin G.B., Shmykova N.A., Monakhova M.A. Fiziologiya rastenii, 1999, 46(6): 876-883 (in Russ.).

15. Takahashi Y., Yokoi S., Takahata Y. Improvement of microspore culture method for multiple samples in Brassica. Breeding Science, 2012, 61: 96-98 (doi: 10.1270/jsbbs.61.96).

16. Na H., Kwak J.H., Chun C. The effect of plant growth regulators, activated charcoal, and Ag$\mathrm{NO}_{3}$ on microspore derived embryo formation in broccoli (Brassica oleracea L. var. italica). Hortic. Environ. Biotechnol., 2011, 52(5): 524-529 (doi: 10.1007/s13580-011-0034-7).

17. Sato S., Katoh N., Iwai S., Hagimori M. Effect of low temperature pretreatment of buds or inflorescence on isolated microspore culture in Brassica rapa (syn. B. campestris). Breeding Science, 2002, 52(1): 23-26 (doi: 10.1270/jsbbs.52.23).

18. Don Palmer C., Keller W.A. Overview of haploidy. In: Haploids in crop improvement II. Biotechnology in agriculture and forestry, vol. 56. C. Don Palmer, W.A. Keller, K.J. Kasha (eds.). Springer, Berlin, Heidelberg, 2005: 3-9 (doi: 10.1007/3-540-26889-8_1).

19. Olmedilla A. Microspore embryogenesis. In: Plant developmental biology - biotechnological perspectives /E. Pua, M. Davey (eds.). Springer, Berlin, Heidelberg, 2010: 27-44 (doi: 10.1007/9783-642-04670-4 2).

20. Peixe A., Barroso J., Potes A., Pais M.S. Induction of haploid morphogenic calluses from in vitro cultured anthers of Prunus armeniaca cv. 'Harcot'. Plant Cell, Tissue and Organ Culture (PCTOC), 2004, 77: 35-41 (doi: 10.1023/b:ticu.0000016498.95516.e6).

21. Zontikov D., Zontikova S., Sergeev R., Sirotina M. Micropropagation of highly productive forms of diploid and triploid aspen. Advanced Materials Research, 2014, 962-965: 681-690 (doi: 10.4028/www.scientific.net/AMR.962-965.681).

22. Zontikov D., Zontikova S., Sergeev R., Shurgin A. In vitro propagation of Rubus chamaemorus L. and Rubus arcticus. Proc. Int. Conf. "14th International multidisciplinary scientific geoconference and EXPO». Albena, 2014: 397-403.

23. Murashige T.A., Skoog F. A revised medium for rapid growth and bio assays with tobacco tissue cultures. Physiologia Plantarum, 1962, 15: 473-497.

24. Pukhal'skii V.A. Tsitologiya i tsitogenetika rastenii [Plant cytology and cytogenetics]. Moscow, 2004 (in Russ.).

25. Shumilina D.V., Shmykova N.A., Bondareva L.L., Suprunova T.P. Effect of genotype and medium culture content on microspore-derived embryo formation in Chinese cabbage (Brassica rapa ssp. chinensis) cv. Lastochka. Biology Bulletin, 2015, 42(4): 302-309 (doi: 10.1134/S1062359015040135).

26. Shmykova N.A., Shumilina D.V., Suprunova T.P. Vavilovskii zhurnal genetiki i selektsii, 2015, 1: 111-120 (doi: 10.18699/VJ15.014) (in Russ.).

27. Lionneton E., Beuret W., Delaitre C., Ochatt S., Rancillac M. Improved microspore culture and doubled haploid plant regeneration in the brown condiment mustard (Brassica juncea). Plant Cell Reports, 2001, 20: 126-130 (doi: 10.1007/s002990000292).

28. Pivovarov V.F., Bondareva N.A., Shmykova N.A., Shumilina D.V., Mineikina A.I. New generation hybrids of white cabbage (Brassica oleracea L. convar. capitate var. alba DC) based on doubled haploids. Sel'skokhozyaistvennaya biologiya [Agricultural Biology], 2017, 52(1): 143-151 (doi: 10.15389/agrobiology.2017.1.143eng).

29. Monakhos S.G., Nguen M.L., Bezbozhnaya A.V., Monakhos G.F. A relationship between ploidy level and the number of chloroplasts in stomatal guard cells in diploid and amphidiploid Brassica species. Sel'skokhozyaistvennaya biologiya [Agricultural Biology], 2014, 5: 44-54 (doi: 10.15389/agrobiology.2014.5.44eng).

30. Yuan S., Liu Y., Fang Z., Yang L., Zhuang M., Zhang Y., Sun P. Study on the relationship between the ploidy level of microspore-derived plants and the number of chloroplast in stomatal guard cells in Brassica oleracea. Agricultural Sciences in China, 2009, 8(8): 939-946 (doi: 10.1016/S1671-2927(08)60298-9).

31. Soroka A.I. Differentiation of haploid and dihaploid rape plants at the cytological and morphological levels. Cytol. Genet., 2013, 47(2): 88-92 (doi: 10.3103/S0095452713020102).

32. Xynias I., Koufalis A., Gouli-Vavdinoudi E., Roupakias D. Factors affecting doubled haploid plant production via maize technique in bread wheat. Acta Biologica Cracoviensia s. Botanica, 2015, 56(2): 67-73 (doi: 10.2478/abcsb-2014-0022).

33. Khokhar M.I., Razaq A., Iqbal J., Anwar M.J., Iqbal M.Z., ur Rehman S. Choice of maize genotype affects wheat haploid seed and success of embryo rescue. RADS Journal of Biological Research and Applied Science, 2019, 10(1): 1-5. 